\title{
Estudo da acessibilidade de idosos ao centro da cidade de Caratinga, MG
}

\author{
Study of the accessibility of aged people to the city center of Caratinga, state of Minas Gerais, \\ Brazil
}

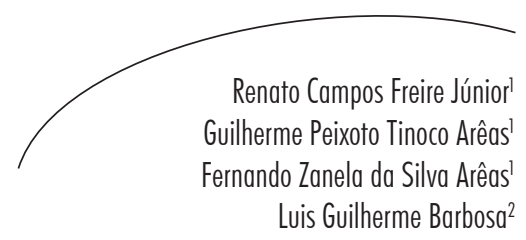

\section{Resumo}

Este estudo, ao abordar a questão da acessibilidade urbana dos idosos, traz à tona a discussão do planejamento do espaço urbano e a importância de se identificar as necessidades dos idosos em relação ao ambiente construído e em relação a seu deslocamento na cidade. Tendo como objetivo discutir a acessibilidade do idoso ao centro da cidade de Caratinga, localizada no Estado de Minas Gerais, realizouse pesquisa exploratória, por meio da aplicação de um formulário de avaliação da usabilidade do espaço urbano a 255 idosos. Por meio da análise descritiva e univariada, o trabalho buscou oferecer uma contribuição científica à discussão da acessibilidade urbana aos idosos, caracterizando seus participantes e identificando os principais problemas de acessibilidade sob o ponto de vista dos mesmos. Os resultados mostraram que a maioria dos idosos entrevistados se locomove a pé (55,3\%). Problemas como obstáculos nas calçadas (66,3\%), aglomeração de pessoas $(63,5 \%)$, dificuldades para atravessar a rua $(55,3 \%)$ e história de quedas no centro $(33 \%)$ foram queixas observadas com frequência. Os registros fotográficos e as sugestões levantadas por esses idosos deram visibilidade às irregularidades e problemas de acessibilidade urbana ao centro de Caratinga.

\section{Abstract}

This study, while approaching the issue of the urban accessibility of the elderly, brings us the discussion of the urban space planning and the importance of identifying the needs of the elderly in relation to the constructed environment and their motion in the city. Aiming to argue the accessibility of the aged one to the center of Caratinga city, state of Minas Gerais, Brazil, an exploratory research was conducted, applying an evaluation form on the usability of the urban space to 255 aged ones. Through descriptive and univariate analysis, the study tried to offer a scientific contribution to the debate of urban accessibility to the elderly, characterizing the participants and identifying the main problems of accessibility in their viewpoint. Interviewed results

Palavras-chave: Idoso. Estruturas de Acesso. Governo Local. Barreiras Arquitetônicas. Acessibilidade Urbana.

\footnotetext{
Instituto de Saúde e Biotecnologia. Universidade Federal do Amazonas. Coari, AM, Brasil.

Programa de Mestrado em Saúde da Família. Universidade Estácio de Sá. Rio de Janeiro, RJ, Brasil.
}

Key words: Elderly. Architectural Accessibility. Local Government. Architectural Barriers. Urban Accessibility. 
showed that most interviewed elderly walk themselves on foot $(55.3 \%)$. Problems as obstacles in the sidewalk (66.3\%), agglomeration of people $(63.5 \%)$, difficulties to cross the street $(55.3 \%)$ and history of falls in the center $(33 \%)$ were frequently observed complaints. The photographic registers and the suggestions raised by these aged gave visibility to the irregularities and problems of urban accessibility in the city center of Caratinga.

\section{INTRODUÇÃO}

Este estudo surgiu a partir da observação e reflexão acerca da mobilidade e utilização do espaço urbano pelo idoso. O Brasil, juntamente com outros países, tem vivenciado o aumento acelerado do número de pessoas com mais de 60 anos de idade. A preocupação com esse contingente tem se tornado cada vez mais urgente, não só por parte dos profissionais de saúde, mas por todas as esferas, políticas e da população em geral, no suprimento de suas necessidades. ${ }^{1}$

Observando as cidades brasileiras, percebese que nem sempre seus espaços são acessíveis a todas as pessoas que lá vivem. A sociedade vive em um meio projetado para pessoas jovens e que não apresenta nenhuma dificuldade de locomoção ou mobilidade reduzida. É comum encontrar em diversas cidades calçadas irregulares ou mesmo com buracos, praças com barreiras físicas e técnicas, sem falar da dificuldade de acesso a bancos, farmácias, supermercados, hospitais e áreas de lazer. ${ }^{2}$ Todas essas barreiras podem prejudicar ou mesmo impedir que um cidadão utilize de forma plena o ambiente onde vive. Dentre os sujeitos em desvantagens, os idosos se apresentam como um público representativo e muitas vezes se veem confinados em suas casas, privando-se de sua participação no convívio social.,4

Para uma velhice saudável, é necessário que haja interação harmoniosa com o meio ambiente. Levando-se em consideração que essa relação vive em constante transformação, variáveis como saúde, nível econômico, idade, raça, emprego, apoio familiar, disponibilidade de transporte, atividades e integração social são elementos importantes desse contexto idoso-ambiente. ${ }^{2} \mathrm{~A}$ preocupação com essa relação é particularmente importante, uma vez que o planejamento do ambiente construído e a acessibilidade urbana são temas emergentes relacionados ao estudo da velhice e do envelhecimento, com poucas investigações publicadas. ${ }^{5}$ Segundo o mesmo autor, a tarefa de projetar ambientes para usuários idosos ainda é tratada de forma bastante superficial, visto que suas necessidades são quase sempre comparadas e reduzidas às necessidades das pessoas com deficiência. O resultado disso são as dificuldades e perigos encontrados nos ambientes urbanos onde os idosos circulam.

Sabe-se que os acidentes por atropelamento e quedas se encontram entre os principais fatores de mortalidade da população idosa. Esses fatores alcançam frações de 64,8 e 58,3 óbitos por 100 mil habitantes, respectivamente. ${ }^{6}$ Guimarães \& Farinatti, ${ }^{7}$ em estudo transversal retrospectivo com 72 idosas, demonstraram que a maioria dos episódios de quedas ocorre na rua, sendo o principal motivo a má conservação dos locais, como buracos, pedras soltas, desníveis, degraus muito altos, pisos instáveis ou escorregadios.

Em termos econômicos, calcula-se hoje que para um projeto concebido de forma adequada às condições de acessibilidade, o acréscimo corresponderia a $1 \%$ do valor da obra. No entanto, ao precisar de adequação ao ambiente depois de construído, esse valor pode alcança $25 \%{ }^{8}$

A Gerontologia Ambiental, área da Gerontologia que se concentra na descrição, explicação e modificação das relações entre idosos e seus contextos socioespaciais, surge então como pedra fundamental para a tarefa de identificar as necessidades dos idosos em relação ao ambiente construído e também ao 
ambiente urbano. Por isso, a integração entre a Engenharia e a Arquitetura com o enfoque multidisciplinar gerontológico, incluindo fisioterapeutas, sociólogos, antropólogos e outros profissionais, se faz necessária. ${ }^{5}$

No Brasil, a norma NBR 9050/20049 estabelece parâmetros para adequação dos ambientes urbanos, além da concepção de desenho universal que tem sido implantada nas discussões sobre acessibilidade. Contudo, uma das grandes dificuldades de se aplicar esse conceito, nos dias de hoje, é o desconhecimento técnico sobre o tema. ${ }^{10}$

Nos últimos anos, várias pesquisas ${ }^{2,10-12}$ vêm buscando uma reflexão mais profunda sobre o ambiente acessível, o qual não só o idoso, mas todas as pessoas com alguma deficiência ou dificuldade de locomoção, possam usar plenamente, com segurança, conforto e eficiência. Essa tendência não é desprovida de causa. Sabese que hoje 123 milhões de brasileiros, ou seja, quase toda a população do Brasil, têm alguma relação direta ou indireta com pessoas com mobilidade diminuída. ${ }^{10}$

A presença de acessibilidade no meio urbano é uma exigência constitucional, cujo objetivo deve ser permitir ganhos de autonomia e de mobilidade a uma porção maior de pessoas, incluindo aquelas que tenham dificuldades de locomoção, para que possam usufruir os espaços urbanos com mais segurança, confiança e comodidade. $^{8}$

De acordo com Fernandes, ${ }^{13}$ o urbanismo como ciência de desenhar as cidades e a arte de construí-las serve como uma ferramenta importante da política pública voltada para desenvolver projetos e ações fundamentadas nesses princípios. Segundo o mesmo autor, um correto planejamento urbano deveria levar em conta que a necessidade do indivíduo de circular ou se deslocar pela cidade pode estar condicionada ao desejo de realizar atividades socioculturais, políticas e econômicas, ${ }^{13}$ que embora sejam elementos intrínsecos ao sujeito, são necessárias ao desenvolvimento da sociedade.
Porisso, o planejamento de ambientes saudáveis e acessíveis em função das necessidades dos usuários vem ganhando destaque e importância. Ao se entender as relações e necessidades pessoais e coletivas, a construção de ambientes abre espaço para discussões e considerações das necessidades de cunho psicológico em relação a esses ambientes, que normalmente não são consideradas no processo de planejamento. ${ }^{14,15}$

O Brasil conta hoje com o Decreto $\mathrm{n}^{\circ}$ $5.296 / 04,{ }^{16}$ que regulamenta a Lei federal $n^{\circ}$ $10.048 / 00$, que dá prioridade de atendimento a pessoas com deficiência, idosos, gestantes, lactantes e pessoas acompanhadas por crianças de colo, e a Lei n ${ }^{0} 10.098 / 00,{ }^{17}$ que estabelece normas gerais e critérios básicos para a promoção da acessibilidade das pessoas com deficiência ou mobilidade reduzida. Esse decreto, juntamente com o Estatuto das Cidades, ${ }^{18}$ o Plano Diretor Municipal ${ }^{19}$ e o Plano de Transporte e Mobilidade Urbana, ${ }^{20}$ compõe um conjunto de instrumentos urbanísticos que orienta todos os segmentos da sociedade que participam da construção das cidades.

Diante das questões apresentadas e considerando a contextualização geográfica, política, cultural e econômica de Caratinga, a situação em que a cidade se encontra atualmente nos remete a questionamentos relacionados à sua acessibilidade - acessibilidade urbana pensada como facilidade de deslocamento, como inserção social e, sobretudo, como autonomia para se alcançar os destinos desejados dentro da cidade, com acesso amplo e democrático. ${ }^{10}$

Além disso, torna-se relevante realizar estudos sobre acessibilidade no intuito de se identificar problemas de acessibilidade urbana, e com base nesses resultados, criar propostas de soluções que promovam a inclusão de todo cidadão, principalmente os que apresentam alguma deficiência ou mobilidade reduzida. Nesse último caso se enquadram, entre outros, as pessoas idosas, população de interesse do presente trabalho, que teve como objetivo discutir a acessibilidade do idoso ao centro da cidade de Caratinga, localizada no Estado de Minas Gerais. 


\section{METODOLOGIA}

Tratou-se de pesquisa descritiva, cujo objetivo foi descrever as características de determinada população por meio da utilização de técnicas padronizadas de coleta de dados, como o questionário. $\mathrm{O}$ procedimento técnico utilizado foi o levantamento, no qual se buscou solicitar informações, ao grupo deidosos, acerca do problema do estudo; a interpretação dos dados coletados se deu pelo método de análise quantitativo. ${ }^{21}$

Quanto ao local do estudo, foi realizado no centro da cidade de Caratinga, Estado de Minas Gerais, tendo como público-alvo os idosos residentes nessa cidade. Embora o município seja determinado por uma parcela urbana e outra rural, o estudo se concentrou no espaço urbano. A escolha se deu pelo fato de a parcela urbana, que se denomina cidade, ser o local onde acontecem as relações mais importantes entre a população, além das trocas e contatos sociais. ${ }^{10} \mathrm{~A}$ pesquisa foi submetida ao Comitê de Ética e Pesquisa do Centro Universitário de Caratinga (UNEC), tendo sido aprovada por meio do parecer no 004/07.

Para se alcançar os objetivos previstos, utilizou-se um formulário de avaliação da usabilidade do espaço urbano (apêndice1) para identificação dos principais locais da cidade de Caratinga frequentados pelos idosos, bem como os principais problemas encontrados pelos mesmos com relação a acessibilidade e deslocamentos na cidade.

Apêndice 1. Formulário de avaliação da usabilidade do espaço urbano

\section{1) Dados de identificação}

Nome: Data de nascimento

Bairro: Local da entrevista:

Ocupação: Fonte de renda:

Sexo: ( ) masculino ( ) feminino

Escolaridade: ( ) analfabeto ( ) $1^{0}$ grau incompleto $(\quad) 1^{\circ}$ grau completo

( ) $2^{\circ}$ grau incompleto ( ) $2^{\circ}$ grau completo ( ) $3^{\circ} \mathrm{grau}$

Possui limitação física: ( ) sim ( ) não Qual?

\section{2) Circulação}

Principal meio de locomoção: ( ) a pé ( ) ônibus ( ) automóvel ( ) motocicleta

( ) outros

Na maior parte das vezes o(a) senhor(a) vai ao centro da cidade sozinho?

( ) $\operatorname{sim}($ ) não Com quem?

Quando o(a) senhor(a) vem ao centro da cidade quais locais frequenta normalmente? (pode marcar mais de um)

( ) bancos ( ) cinema ( ) farmácias ( ) praças públicas ( ) supermercados

( ) restaurantes ( ) loterias ( ) bares ( ) hospital ( )postos de saúde

( ) consultórios médicos ( ) igrejas ( ) padarias ( ) grupos de terceira idade

( ) outros: 
$\mathrm{O}$ (a) senhor(a) gostaria de registrar algumas dificuldades de se chegar aos locais citados anteriormente?

Durante a semana quais dias o(a) senhor(a) normalmente sai de casa? (pode marcar mais de um)

( ) segunda ( ) terça ( ) quarta ( ) quinta ( ) sexta ( ) sábado ( ) domingo

Na sua avaliação qual o grau de dificuldade de atravessar as ruas da cidade?

( ) muito difícil ( ) difícil ( ) fácil ( ) muito fácil

\section{3) Identificação de problemas}

$\mathrm{O}(\mathrm{a})$ senhor(a) identifica alguns desses problemas para atravessar a rua? (pode marcar mais de um) Falta de rampas nas calçadas ( )

Impaciência dos motoristas, não respeitam a sinalização ( )

O tempo de sinal aberto é insuficiente para conseguir atravessar a rua ( )

Falta sinal para pedestres ( )

Tenho dificuldades de enxergar o sinal de pedestres ( )

Não há faixa para travessia de pedestres ( )

Local para travessia com buracos e piso irregulares ( )

Outros:

$\mathrm{O}(\mathrm{a})$ senhor(a) identifica alguns desses problemas para andar na calçada? (pode marcar mais de um)

Falta de calçadas ( )

Calçadas irregulares e com buracos ( )

Calçadas muito inclinadas ( )

Calçadas estreitas, que me obrigam a andar na rua $(\quad)$

Presença de ciclistas nas calçadas ( )

Presença de obstáculos no meio da calçada (árvores, lixeiras, caçambas de entulho)

Quais?

Presença de animais nas calçadas que atrapalham caminhar com tranquilidade ( )

Pisos escorregadios ( )

Aglomeração de pessoas na calçada ( )

O(a) senhor(a) já caiu na rua? ( ) sim ( ) não

Qual o motivo?

Existe algum local da cidade que o(a) senhor(a) não frequenta por dificuldades de acesso, mas que gostaria de frequentar? ( ) sim ( ) não

Qual?

Quais sugestões o(a) senhor(a) daria para melhorar o acesso/deslocamento dos idosos em Caratinga? 
O formulário de avaliação da usabilidade foi dividido em três domínios: dados de identificação, circulação e identificação de problemas. O formulário foi aplicado aos idosos que concordaram em participar da pesquisa e assinaram o Termo de Consentimento Livre e Esclarecido (TCLE), pelo pesquisador responsável e uma equipe de cinco colaboradores previamente treinados. Para o cálculo amostral, utilizou-se como referência o tamanho da população idosa de Caratinga em 2006, ${ }^{22}$ que era de 8.328 pessoas com mais de 60 anos, sendo determinado como tamanho representativo de amostra $n=382$ idosos.

A coleta de dados aconteceu no centro da cidade de Caratinga, entre setembro de 2008 e janeiro de 2009. A determinação dessa forma de coleta se deu pela possibilidade de o idoso identificar melhor os problemas de acessibilidade no momento em que estivesse caminhando no centro.

As informações coletadas foram digitadas em um banco de dados desenvolvido no programa da Microsoft Office Excel ${ }^{\circledR}$ versão 2007. Os resultados descritivos apresentados na seção de resultados foram obtidos utilizando frequências e porcentagens para as características das diversas variáveis categóricas e da obtenção de medidas de tendência central (média e mediana) e medida de dispersão (desvio-padrão) para idade.

Realizou-se uma comparação de todas as variáveis com a idade dos idosos, categorizada em 60 a 79 anos e 80 a 93 anos, a partir de tabelas de contingência, sendo aplicado o teste qui-quadrado de Pearson para comparação de proporções. Quando uma das frequências esperadas foi menor que cinco, foi utilizado o teste de Fisher. A categoria considerada como padrão está indicada nas tabelas de resultados, com o valor 1,0 na coluna dos valores de odds ratio (OR). A análise univariada foi feita por meio do software $\mathrm{R}$, de domínio público.

O desenho de estudo empregado neste trabalho buscou agregar o conceito de design social, que foi descrito pela primeira vez por Sommer em 1983, que defende a participação do usuário na discussão e construção do ambiente, a fim de atender a suas necessidades da melhor forma. ${ }^{5}$ Esse processo envolve etapas a serem seguidas, como: estudo das necessidades dos usuários, envolvimento dos mesmos e a tradução de suas necessidades em orientações.

\section{RESULTADOS}

A amostra final obtida foi de 255 idosos. Embora não tenha alcançado o tamanho amostral calculado no projeto, crê-se que esse número foi significativo, uma vez que para o primeiro cálculo não se levou em consideração a população de idosos acamados ou que possuíam graus elevados de imobilidade. A idade média dos participantes foi de 70 anos $( \pm 6,8)$ e a maioria dos entrevistados pertencia ao gênero masculino $(66,7 \%)$.

Com relação ao local da entrevista, selecionaram-se quatro pontos principais do centro da cidade: Praça Cesário Alvim, Praça Getúlio Vargas, Praça Dom Pedro II e Avenida Olegário Maciel. $\mathrm{Na}$ variável relacionada ao bairro onde o idoso residia, percebeu-se que a amostra ficou bem distribuída, alcançando moradores de quase todos os bairros da cidade, inclusive os distritos. A maioria, porém, residia no centro de Caratinga (23,7\%).

A caracterização sociodemográfica dos idosos participantes da pesquisa apresentou concordância com amostras de outros estudos relacionados à velhice. ${ }^{1,23-26}$ Contudo, diferiu-se com a proporção entre o número de homens e mulheres, demonstrando valor maior para os idosos (66,7\%), em relação às idosas (33,3\%). A maior parte dos idosos era de aposentados $(76,9 \%)$, do sexo masculino $(66,7 \%)$ e com escolaridade igual ou inferior ao primeiro grau incompleto $(60 \%)$.

A tabela 1 apresenta as frequências das variáveis categóricas relacionadas com as características de circulação. A maior parte se locomovia a pé $(55,3 \%)$ e os locais mais frequentados eram bancos $(72,5 \%)$, farmácias $(66,7 \%)$, supermercados $(67,5 \%)$ e igrejas $(73,3 \%)$. Curiosamente, poucos idosos declararam frequentar grupos de terceira idade. Os idosos saíam mais nos dias de semana do que nos fins de semana, sendo a segunda-feira o dia que mais iam ao centro $(78,8 \%)$. 
Tabela 1 - Descrição da amostra, segundo características de circulação. Caratinga-MG, 2008-2009.

\begin{tabular}{|c|c|c|}
\hline \multirow[b]{2}{*}{ Variável } & \multicolumn{2}{|c|}{ Frequência } \\
\hline & $\mathrm{n}$ & $\%$ \\
\hline \multicolumn{3}{|l|}{ Principal meio de locomoção } \\
\hline A pé & 141 & 55,3 \\
\hline Ônibus & 79 & 31,0 \\
\hline Automóveis & 32 & 12,5 \\
\hline Moto & 2 & 0,8 \\
\hline Outros & 1 & 0,4 \\
\hline \multicolumn{3}{|l|}{ Outros meios de locomoção } \\
\hline Não & 241 & 94,5 \\
\hline Bicicleta & 10 & 3,9 \\
\hline Cadeirante & 3 & 1,2 \\
\hline Cavalo & 1 & 0,4 \\
\hline Vai ao centro sozinho & 208 & 81,6 \\
\hline \multicolumn{3}{|l|}{ Com quem } \\
\hline Sem relato & 1 & 2,1 \\
\hline Irmãos & 6 & 12,8 \\
\hline Filho/neto/cônjuge & 36 & 76,6 \\
\hline Cuidador/amigo & 4 & 8,5 \\
\hline \multicolumn{3}{|l|}{ Quando vai ao centro, quais locais frequenta* } \\
\hline Bancos & 185 & 72,5 \\
\hline Farmácias & 170 & 66,7 \\
\hline Supermercados & 172 & 67,5 \\
\hline Loterias & 69 & 27,1 \\
\hline Hospital & 34 & 13,3 \\
\hline Consultórios médicos & 72 & 28,2 \\
\hline Padarias & 117 & 45,9 \\
\hline Cinema & 1 & 0,4 \\
\hline Praças públicas & 126 & 49,4 \\
\hline Restaurantes & 56 & 22 \\
\hline Bares & 35 & 13,7 \\
\hline Postos de saúde & 88 & 34,5 \\
\hline Igrejas & 187 & 73,3 \\
\hline Grupos de terceira idade & 16 & 6,3 \\
\hline
\end{tabular}




\begin{tabular}{|c|c|c|}
\hline \multirow[b]{2}{*}{ Variável } & \multicolumn{2}{|c|}{ Frequência } \\
\hline & $\mathrm{n}$ & $\%$ \\
\hline \multicolumn{3}{|l|}{ Outros locais que frequenta } \\
\hline Não & 236 & 92,6 \\
\hline Visita a familiares e amigos & 2 & 0,8 \\
\hline Rodoviária & 1 & 0,4 \\
\hline Lojas comerciais & 12 & 4,7 \\
\hline Hidroginásticas & 1 & 0,4 \\
\hline Fisioterapia & 1 & 0,4 \\
\hline Oficina mecânica & 1 & 0,4 \\
\hline Caminhar & 1 & 0,4 \\
\hline \multicolumn{3}{|l|}{ Dias da semana que sai de casa* } \\
\hline Segunda-feira & 201 & 78,8 \\
\hline Terça-feira & 174 & 68,2 \\
\hline Quarta-feita & 184 & 72,2 \\
\hline Quinta-feira & 180 & 70,6 \\
\hline Sexta-feira & 177 & 69,7 \\
\hline Sábado & 128 & 50,2 \\
\hline Domingo & 140 & 54,9 \\
\hline
\end{tabular}

* Questões de respostas múltiplas

Sobre os locais que os idosos frequentavam, foi perguntado se identificavam dificuldades de locomoção nesses trajetos. Dentre as dificuldades encontradas, destacou-se o trânsito, seguido por problemas na calçada. Mais da metade das pessoas relataram que é difícil ou muito difícil atravessar a rua, e que o principal problema é a impaciência dos motoristas (tabela 2). 
Tabela 2 - Descrição da amostra, segundo dificuldade de atravessar a rua. Caratinga-MG, 2008-2009.

\begin{tabular}{|c|c|c|}
\hline \multirow[b]{2}{*}{ Variável } & \multicolumn{2}{|c|}{ Frequência } \\
\hline & $\mathrm{n}$ & $\%$ \\
\hline \multicolumn{3}{|l|}{ Registro de dificuldades nos locais citados } \\
\hline Sem relato & 230 & 90,2 \\
\hline Travessia da BR 116 & 2 & 0,8 \\
\hline Problemas nas calçadas & 7 & 2,8 \\
\hline Estacionamento & 1 & 0,4 \\
\hline Trânsito & 10 & 3,9 \\
\hline Impaciência dos motoristas e pedestres & 1 & 0,4 \\
\hline Morros & 1 & 0,4 \\
\hline Dificuldade de subir nos ônibus & 3 & 1,2 \\
\hline \multicolumn{3}{|l|}{ Para atravessar a rua } \\
\hline Muito difícil & 36 & 14,1 \\
\hline Difícil & 105 & 41,2 \\
\hline Fácil & 111 & 43,5 \\
\hline Muito fácil & 3 & 1,2 \\
\hline \multicolumn{3}{|l|}{ Problemas para atravessar a rua* } \\
\hline Falta de rampas & 77 & 30,2 \\
\hline Impaciência dos motoristas & 167 & 65,5 \\
\hline O tempo do sinal é insuficiente & 65 & 25,5 \\
\hline Falta sinal para pedestres & 96 & 37,7 \\
\hline Dificuldade de enxergar o sinal & 27 & 10,6 \\
\hline Não há faixa para travessia de pedestre & 89 & 34,9 \\
\hline Local de travessia irregular & 63 & 24,7 \\
\hline Outros problemas para atravessar a rua & 254 & 99,6 \\
\hline
\end{tabular}

* Questões de respostas múltiplas 
A tabela 3 apresenta as frequências das variáveis categóricas relacionadas às dificuldades na calçada.

Tabela 3 - Descrição da amostra, segundo dificuldade na calçada. Caratinga, Minas Gerais, 2008-2009.

\begin{tabular}{|c|c|c|}
\hline \multirow[b]{2}{*}{ Variável } & \multicolumn{2}{|c|}{ Frequência } \\
\hline & $\mathrm{n}$ & $\%$ \\
\hline \multicolumn{3}{|l|}{ Problemas para andar na calçada* } \\
\hline Falta de calçadas & 83 & 32,5 \\
\hline Calçadas irregulares & 92 & 36,1 \\
\hline Calçadas muito inclinadas & 56 & 22 \\
\hline Calçadas estreitas & 113 & 44,3 \\
\hline Presença de ciclistas nas calçadas & 144 & 56,5 \\
\hline Presença de obstáculos nas calçadas & 169 & 66,3 \\
\hline \multicolumn{3}{|l|}{ Quais obstáculos* } \\
\hline Nenhum & 86 & 33,7 \\
\hline Carros & 2 & 0,8 \\
\hline Camelôs e bancas de lojas & 138 & 54,1 \\
\hline Ponto de ônibus & 1 & 0,4 \\
\hline Mesas de bares & 8 & 3,1 \\
\hline Entulhos, caçambas e construções & 20 & 7,8 \\
\hline Presença de animais na calçada & 19 & 7,5 \\
\hline Pisos escorregadios & 24 & 9,4 \\
\hline Aglomeração de pessoas na calçada & 162 & 63,5 \\
\hline Quedas na rua & 84 & 32,9 \\
\hline \multicolumn{3}{|l|}{ Motivos das quedas } \\
\hline Sem relato & 0 & 0,0 \\
\hline Tropeção/escorregão & 51 & 60,7 \\
\hline Vertigem e perda súbita de equilíbrio & 5 & 6,0 \\
\hline Pisou no buraco & 21 & 25,0 \\
\hline Esbarrou nos obstáculos na calçada & 2 & 2,4 \\
\hline Atropelado por bicicleta & 5 & 5,9 \\
\hline
\end{tabular}

* Questões de respostas múltiplas 
Nas análises de comparação entre as variáveis estudadas com a idade, observou-se diferença com significância estatística $(\mathrm{p} \leq 0,05)$ para $\mathrm{o}$ principal meio de locomoção (tabela 4). Nota-se, por exemplo, maior proporção dos idosos que não andavam a pé entre os mais novos.

Tabela 4 - Comparação das variáveis categóricas por idade relacionando com a circulação. Caratinga-MG, 20082009.

\begin{tabular}{|c|c|c|c|c|c|c|c|}
\hline \multirow{3}{*}{ Covariável } & \multicolumn{4}{|c|}{ Idade (anos) } & \multirow{3}{*}{ Valor-p } & \multirow{3}{*}{ OR } & \multirow{3}{*}{$\begin{array}{r}\text { IC } \\
95 \%\end{array}$} \\
\hline & \multicolumn{2}{|c|}{60 a 79} & \multicolumn{2}{|c|}{80 a 93} & & & \\
\hline & $\mathrm{n}$ & $\%$ & $\mathrm{n}$ & $\%$ & & & \\
\hline \multicolumn{8}{|c|}{ Principal meio de locomoção } \\
\hline A pé & 123 & 53,0 & 18 & 78,3 & 0,020 & 1,0 & \\
\hline Outros & 109 & 47,0 & 5 & 21,7 & & 3,2 & 1,1 a 10,2 \\
\hline \multicolumn{8}{|c|}{ Outros meios de locomoção } \\
\hline Não & 218 & 94,0 & 23 & 100,0 & $0,623 *$ & $\ldots$ & \\
\hline Outros & 14 & 6,0 & 0 & 0,0 & & & \\
\hline \multicolumn{8}{|l|}{ Vai ao centro sozinho } \\
\hline $\operatorname{Sim}$ & 189 & 81,5 & 19 & 82,6 & $1,000^{*}$ & 1,0 & \\
\hline Não & 43 & 18,5 & 4 & 17,4 & & 1,1 & 0,3 a 4,0 \\
\hline
\end{tabular}

*Teste exato de Fisher;

OR: Odis Ratio; IC: Intervalo de confiança

Nas comparações entre as variáveis relacionadas à dificuldade na calçada e no ato de atravessar a rua, com a idade, não se observou diferença com significância estatística $(\mathrm{p} \leq 0,05)$. Ao se perguntar aos idosos sobre sugestões para melhorar o acesso/deslocamento ao centro da cidade de Caratinga, 165 idosos (64,7\%) responderam a esta pergunta.

Pôde-se perceber que a maioria das sugestões levantadas pelos idosos referiu-se à adequação dos obstáculos encontrados nas calçadas (16,36\%), que dificultavam o deslocamento pelo centro da cidade; a melhoria da infraestrutura das calçadas (15,75\%), devido à presença de buracos, além das dimensões das mesmas; e a necessidade de maior respeito no trânsito por parte dos motoristas $(10,3 \%)$, principalmente dos motociclistas.

Fato curioso encontrado nos resultados foi a reivindicação dos idosos por um transporte coletivo adaptado a eles. Embora não tenha sido objetivo deste trabalho analisar a acessibilidade aos ônibus, percebeu-se que o assunto merece reflexão, entendendo-se que a sugestão levantada pelos idosos possa ser indício de um serviço de transporte coletivo que não atende de forma satisfatória aos usuários idosos. A adequação dos ciclistas no trânsito também foi uma sugestão que se destacou na fala dos idosos $(9,7 \%)$. 


\section{DISCUSSÃO}

Antes de comentar os principais achados deste estudo, algumas questões peculiares a respeito das características da amostra merecem uma reflexão destacada. Ao se pesquisar outros trabalhos que tratam do envelhecimento, ${ }^{23-26}$ observa-se uma concordância quanto ao fenômeno ser preferencialmente feminizado, ou seja, existe maior proporção de mulheres idosas, comparadas aos homens. Esse fato é explicado, principalmente, pela menor mortalidade encontrada na população feminina. Em consequência, quanto mais velho o contingente estudado, maior a proporção de mulheres. E mais, no Brasil a predominância feminina entre os idosos é considerada um fenômeno tipicamente urbano. ${ }^{27}$

Entretanto, o que se observou nesta pesquisa foi a maior participação de homens idosos em relação às idosas na composição amostral. Uma explicação possível para este fato pode estar na maior presença dos homens nas praças da cidade de Caratinga. Durante a coleta dos dados, pôde-se perceber que a maioria dos idosos que frequentavam essas praças, principalmente a Praça Cesário Alvim, eram homens que se encontravam nos grupos de amigos para jogos de baralho e conversas. Não foram encontradas na literatura científica explicações para esse comportamento ou, ainda, outros estudos que avaliassem diferenças na proporção de gênero dentro de amostras de pesquisas com idosos. As outras categorias sociodemográficas corroboram as características do idoso brasileiro. ${ }^{26,28,29}$

Um achado interessante foi quanto à presença de limitação física. Embora em observações de campo se pudessem perceber algumas dificuldades de locomoção ou de agilidade nos idosos, a maioria dos participantes $(84,3 \%)$ não relatou limitações físicas.

Parahyba \& Simões ${ }^{30}$ utilizando informações dos Suplementos de Saúde da Pesquisa Nacional por Amostra de Domicílios (PNAD), identificaram a prevalência de incapacidade funcional em idosos no Brasil. Segundo esses autores, as mulheres declaram incapacidade funcional em maior proporção que os homens. Essa desigualdade de gênero nas condições de saúde pode ser uma explicação razoável para os dados encontrados no presente trabalho. Além disso, convém destacar que essa atitude positiva com relação à limitação física pode ser um fator de proteção contra o desenvolvimento da incapacidade funcional. ${ }^{31}$

O espaço urbano, sendo considerado um conjunto de espaços edificados e livres, é um ambiente onde as relações sociais afloram. Sendo assim, sociedade e espaço não podem ser vistos desvinculadamente. ${ }^{10}$ Outro ponto diz respeito aos problemas que as cidades podem vivenciar em decorrência do seu crescimento, como: déficit habitacional; poluição do ar; das águas e visual; carência de infraestrutura básica; dificuldades de locomoção, e consequentemente, diminuição da qualidade de vida de seus habitantes. ${ }^{4}$ Esses problemas podem ainda se tornar mais preocupantes quando se trata de cidades situadas em regiões geográficas montanhosas ou de construção histórica sem planejamento, como é o caso da cidade de Caratinga.

Dentro dos resultados referentes às características de circulação dos idosos, observou-se que o principal meio de locomoção foi a pé $(55,3 \%)$, seguido pelo transporte de ônibus coletivo (31\%). Segundo o Instituto de Planejamento Econômico Aplicada (IPEA), ${ }^{32}$ nas cidades brasileiras, mais de $30 \%$ dos deslocamentos diários da população são feitos exclusivamente a pé. Talvez por se tratar de uma cidade de médio porte, com população de aproximadamente 84 mil habitantes, ${ }^{19}$ as porcentagens em Caratinga tenham sido ainda maiores em relação à média nacional. Além do mais, neste estudo se considerou que a locomoção selecionada fosse a mais usada, não sendo necessariamente exclusiva.

Pizzol \& Ribeiro ${ }^{14}$ estudaram o cotidiano urbano, por meio do uso e mobilidade nos passeios públicos em quatro bairros de João 
Pessoa, PB. Segundo seus resultados, 36\% da população circulavam a pé. O transporte coletivo foi o mais citado, com $42 \%$.

O desejo de realizar atividades sociais, culturais, políticas e econômicas, que podem ser consideradas necessárias ao desenvolvimento da sociedade, estão sempre ligadas ao ato de circular ou circulação urbana. Para Vasconcellos apud ${ }^{14}$ a forma mais básica, direta e universal de meio de transporte individual é andar a pé. Seguindo esse raciocínio, entende-se que os passeios públicos são o meio físico onde o homem realiza o ato de caminhar, utilizando-o como meio de transporte para suas atividades cotidianas. ${ }^{14}$

O Ministério das Cidades $^{10}$ considera a circulação como o elo de toda ação da mobilidade urbana. Os locais que os idosos entrevistados mais frequentavam quando iam ao centro foram igrejas $(73,3 \%)$, bancos $(72,5 \%)$, supermercados (67,5\%) e farmácias (66,7\%). Aqui ficou demonstrado que o centro tem realmente sido um local de relações sociais. Para esses idosos, o centro reflete uma área dinâmica, onde se encontram o comércio e os lugares de trabalho mais significativos, onde se concentra o maior movimento e onde se ligam a diversas finalidades, sejam econômicas, religiosas ou sociais. $^{4,10}$

Um fato curioso que a princípio não se esperava encontrar foi o número reduzido de idosos que participavam de grupos de terceira idade: apenas 16\%. Mais uma vez, pode-se utilizar o número reduzido de mulheres na amostra como uma explicação plausível para este fato. Debert, ${ }^{33} \mathrm{em}$ sua obra $A$ reinvenção da velhice, discute com muita propriedade em um de seus capítulos os chamados "programas para a terceira idade". Segundo a autora, no Brasil esses programas têm mobilizado sobretudo o público feminino, sendo perfeitamente possível observar o contraste do entusiasmo manifestado pelas mulheres na realização dessas atividades de grupos de terceira idade com a atitude de reserva e indiferença dos homens. Ela ainda completa que nos movimentos dos aposentados, essa razão dos sexos se inverte, sobressaindo a classe masculina de idosos.

Ressalta-se que os locais considerados de lazer no centro da cidade de Caratinga, como bares e restaurantes, são pouco frequentados pelos idosos. A praça pública, no entanto, era frequentada pela metade dos idosos entrevistados. Mais uma vez é destacada a importância das praças como espaços urbanos de convivência, lazer e construção de relações sociais. ${ }^{13}$ Pelas observações de campo, pôde-se constatar que as relações estabelecidas e as atividades realizadas por esses idosos, principalmente na Praça Cesário Alvim, deram a esse espaço urbano um significado muito maior do que apenas físico. A noção de espaço transcende o físico, implicando representação e significação simbólica ${ }^{34}$ para o sujeito que se relaciona nesse meio (por exemplo: ambiente hostil, tenso, não confortável, ou agradável e satisfatório, como no caso dos idosos deste trabalho).

O município de Caratinga possui um Plano Diretor $^{19}$ participativo (Lei $\left.\mathrm{n}^{\mathrm{o}} 3.025 / 2007\right),{ }^{35}$ onde em seu artigo 79 , capítulo 6 , faz referência ao lazer, colocando a terceira idade, a infância e a adolescência como grupos prioritários na criação de ambientes urbanos de atividades de lazer. Assim, faz-se necessário realizar estudos posteriores para investigar possíveis espaços urbanos onde possam ser oferecidas atividades de lazer e recreação que alcancem todos os idosos do município de Caratinga.

Ao se discutir acessibilidade urbana, a calçada é o local mais avaliado, devendo ser observados: o material empregado na área do passeio público, as transposições de um lado para outro da via pública, as formas de travessia e as configurações do mobiliário urbano. ${ }^{10}$ Este trabalho procurou identificar problemas nas calçadas levantados pelos idosos. Segundo os idosos, os maiores problemas encontrados nas calçadas do centro da cidade foram obstáculos (66,3\%), aglomeração de pessoas $(63,5 \%)$, presença de ciclistas $(56,5 \%)$ e calçadas estreitas $(44,3 \%)$. 
O Programa Brasil Acessível, do Ministério das Cidades, discute os problemas encontrados nas calçadas das cidades brasileiras e identificou a falta de controle de planejamento dos espaços urbanos e a permissividade desenfreada de ações particulares sobre o uso coletivo como os principais protagonistas. ${ }^{10}$

Os principais obstáculos encontrados pelos idosos nas calçadas do centro da cidade foram a presença dos camelôs e bancas de lojas, entulhos, caçambas e materiais de construção. Esses obstáculos representam um grande conflito nos deslocamentos e o livre movimento das pessoas nas calçadas públicas. Se levarmos em consideração a mobilidade reduzida das pessoas mais velhas, em decorrência do processo do envelhecimento, esses obstáculos se tornam verdadeiros complicadores para o uso dos espaços urbanos por esses indivíduos. A presença de materiais atrapalhando o trânsito das pessoas nas calçadas deve ser considerada um problema de planejamento ambiental da via pública:

[.. a locação de mobiliário sem planejamento, sua ampliação não autorizada, objetos comercializados sobre a calcada, os diversos usuários de um mesmo espaço com suas modalidades específicas, o desenho urbano das calçadas entre eles, a inclinação transversal da mesma, a implantação da vegetação de forma desordenada, a falta de manutenção são alguns dos problemas que se podem encontrar nos espaços urbanos onde há circulação de pessoas. (Brasil, Ministério das Cidades, 2005, p.53).

Ao se reportar à NBR $12.255,{ }^{36}$ que trata da execução e utilização dos passeios públicos, compreendem-se esses espaços como destinados fundamentalmente ao trânsito das pessoas, devendo ainda possuir condições para o trânsito adequado de pessoas com deficiência ou mobilidade reduzida.

Cabe ressaltar, neste momento do trabalho, que as observações realizadas pelo pesquisador e colaboradores na coleta dos dados vêm ao encontro das respostas dos idosos. A falta de normatização das calçadas, no aspecto construtivo, e até mesmo o próprio mobiliário urbano, como orelhões, lixeiras, placas de sinalização, entulhos, veículos estacionados, bancas, mesas, cadeiras e degraus dificultavam a mobilidade dos pedestres no centro da cidade.

Para que as políticas de desenvolvimento urbano e as funções sociais da cidade possam ser desenvolvidas, o município conta com o Plano Diretor, um instrumento básico para a implantação da política urbana, em que as decisões que interferem no futuro da cidade, no futuro e na vida de cada cidadão estão amplamente asseguradas por lei. $\mathrm{Na}$ cidade de Caratinga, o Plano Diretor ${ }^{19}$ resguarda os direitos dos pedestres no seu artigo 64. Destaca que as barreiras arquitetônicas devem ser removidas e os passeios tratados com uniformidade e materiais apropriados à segurança de pedestres, mesmo aqueles pertencentes aos grupos especiais, garantindo-lhes conforto e acessibilidade. Outro documento importante que resguarda os direitos das pessoas mais velhas é o Estatuto do Idoso, ${ }^{37}$ onde se encontra, no artigo 38, inciso II, a determinação para que as barreiras arquitetônicas ou urbanísticas sejam eliminadas, garantindo-se assim a acessibilidade do idoso.

Ainda em relação à mobilidade nos passeios públicos, observou-se que quase um terço dos idosos entrevistados relatou história de quedas na rua. Desses, mais da metade caíram por tropeções, escorregões ou pisando em buracos. Esse fato é importante e merece atenção maior, pois se sabe que a queda é um grande problema na Geriatria e Gerontologia, e que pode trazer várias consequências negativas, levando inclusive à morte. As quedas se encontram entre os fatores de risco de morte para idosos residentes na zona urbana, ${ }^{28}$ podendo levar o idoso ao isolamento social e alterando sua mobilidade. ${ }^{7,11,38}$ Além disso, as pessoas idosas têm dificuldade em manter o equilíbrio sob condições de conflito sensorial ${ }^{7}$ como, por exemplo, quando se deslocam em calçadas com aglomeração de pessoas ou andam próximas a um fluxo de veículos em velocidade.

Prado, ${ }^{2}$ em sua dissertação onde realizou estudo da acessibilidade do idoso em dois bairros 
de São Paulo, nos alerta para o perigo que os desenhos dos pisos nos ambientes externos podem trazer para as pessoas com perdas visuais e neurológicas, causando ilusão de ótica. Além disso, áreas com piso mal conservado, com desníveis e buracos, apresentam grande risco de provocar entorse ou tombos àqueles que estão com a sensibilidade tátil diminuída ou perdendo força muscular. ${ }^{2}$

Segundo Rozestraten, ${ }^{39}$ é comum se deparar com idosos se chocando com o mobiliário urbano e com as pessoas, principalmente em decorrência da diminuição da visão periférica observada após os 60 anos. Por isso, hoje se observam dados demonstrando o crescente número de eventos relacionados à queda e atropelamento de idosos nas cidades brasileiras. ${ }^{6}$

Essas reflexões podem também ajudar a justificar a dificuldade relatada pelos idosos pesquisados para atravessar as ruas do centro da cidade, tarefa classificada como difícil ou muito difícil por mais da metade dos entrevistados. Não é complicado entender esse achado, uma vez que a capacidade funcional e a agilidade dos idosos estão diminuídas em relação à população mais jovem. No entanto, os principais problemas observados pelos idosos para atravessar a rua foram impaciência dos motoristas (65,7\%), seguida pelo número insuficiente de semáforos para pedestres $(38 \%)$ e faixas nos locais de travessia $(35 \%)$.

Ao se falar no uso da via pública pelas pessoas, principalmente os que apresentam alguma deficiência ou mobilidade reduzida, como os idosos, deve-se atentar para o deslocamento que elas fazem no momento que necessitam transpassar de uma quadra para outra. Nesse evento, a travessia, a pessoa enfrenta uma área de conflito de usos entre veículos e pessoas. Para esses cruzamentos de vias e travessia de pistas, há determinadas recomendações e parâmetros a serem respeitados. ${ }^{10}$

Os artigos 62 e 63 do Plano Diretor ${ }^{19}$ do município de Caratinga contemplam a segurança no trânsito, por meio do disciplinamento das áreas destinadas ao trânsito e acomodação exclusiva de pedestres, sinalização adequada das vias públicas e fiscalização dos limites de velocidade permitidos.

Para todos os pontos de travessia, é necessário haver faixas de pedestres pintadas de forma técnica e rampas de acesso ao nível da travessia. A velocidade de deslocamento das pessoas também é informação importante e que deve ser levada em consideração nos projetos urbanísticos. $\mathrm{Na}$ maioria das cidades brasileiras, utiliza-se uma velocidade de deslocamento de $1,2 \mathrm{~m} / \mathrm{s}$ como parâmetro para o cálculo do tempo de abertura de um semáforo. Considerando que a velocidade média de marcha de um idoso é $0,4 \mathrm{~m} / \mathrm{s}$, fica claro que esse grupo terá grandes dificuldades para realizar a travessia, podendo ainda justificar o número de atropelamentos de idosos..$^{10}$

Não foi objetivo deste trabalho avaliar o tempo de abertura dos semáforos do centro da cidade de Caratinga. Contudo, a queixa da impaciência dos motoristas pode estar ligada à velocidade com que esses idosos entrevistados atravessam a rua. Além disso, quase um terço identificou como problema o tempo de abertura do semáforo para pedestres, que é insuficiente para a travessia.

Embora não tenha sido destacada pelos idosos que participaram deste trabalho, a boa iluminação nas travessias de pedestres é um aspecto observado por alguns autores. A redução das pupilas após os 60 anos de idade compromete a quantidade de luz que chega à retina. $\mathrm{O}$ resultado dessa alteração se traduz na dificuldade para discriminar sombras, cantos e contrastes, que pode ser compensada pelo aumento do nível de iluminação. ${ }^{39}$

Na cidade do Rio de Janeiro, essa questão foi levada em consideração colocando-se nas ruas do bairro Leblon uma iluminação para pedestres diferente da iluminação para veículos, com postes com focos de luz em alturas diferentes, garantindo a segurança da circulação das pessoas nas calçadas. ${ }^{2}$ 
Por fim, algumas limitações do presente estudo devem ser destacadas, como a ausência da utilização de instrumentos que avaliassem as limitações funcionais dos idosos entrevistados e a não investigação da acessibilidade para se chegar ao centro da cidade, como por exemplo, o acesso ao transporte coletivo, limitando-se apenas às questões do próprio centro.

\section{CONCLUSÃO}

O presente estudo demonstrou, com base nas respostas desses idosos, que a questão da acessibilidade urbana pode e deve ser discutida entre a população que vive na cidade e que é usuária desse espaço. Pôde-se observar, nas sugestões e problemas levantados, que as soluções são possíveis, simples e de custo relativamente não elevado, embora o centro estudado pertença a uma cidade antiga e que não foi contemplada ao longo de sua história com um planejamento de crescimento urbano. Acrescenta-se o fato de Caratinga se localizar em uma região montanhosa, onde os problemas arquitetônicos podem se tornar mais relevantes.

O poder público municipal tem a responsabilidade de garantir a função social da cidade, e a acessibilidade urbana deve ter espaço garantido nas discussões e agendas das políticas públicas, buscando reduzir as desigualdades sociais e promover a justiça social e a qualidade de vida urbana.

Crê-se que este estudo possa servir de referência para futuras negociações com o poder público e a sociedade civil, por melhores condições de acessibilidade a todos, mas principalmente aos idosos, atores principais deste trabalho.

\section{REFERÊNCIAS}

1. Camarano AA. Envelhecimento da população brasileira: uma contribuição demográfica. In: Freitas EV, Py L, Cançado FAX, Doll J, Gorzoni ML, organizadores. Tratado de geriatria e gerontologia. 2. ed. Rio de Janeiro: GuanabaraKoogan; 2006. p. 88-105.

2. Prado ARA. A cidade e o idoso: um estudo da questão de acessibilidade nos bairros Jardim de Abril e Jardim do Lago no município de São Paulo [dissertação de Mestrado]. São Paulo: Pontifícia Universidade Católica; 2003.

3. Licht FB, Prado ARA. Idosos, cidade e moradia: acolhimento ou confinamento? Rev Kairós 2002;5(2):67-80

4. Pizzol KMSA. A dinâmica urbana: uma leitura da cidade e da qualidade de vida no urbano. Rev Caminhos Geografia 2006;7(17):1-7.

5. Tomasini SLV. Envelhecimento e planejamento do ambiente construído: em busca de um enfoque interdisciplinar. Rev Bras Ciên Envelh Hum 2005;2(1):76-88

6. Mathias TAF, Jorge MHPM, Andrande OG.

Morbimortalidade por causas externas na população idosa residente em município da região Sul do Brasil. Rev Latino-Am Enferm 2006;14(1):17-24.

7. Guimarães JMN, Farinatti PTV. Análise descritiva de variáveis teoricamente associadas ao risco de quedas em mulheres idosas. Rev Bras Med Esporte 2005; 11(5):299-305.

8. Prado ARA, coordenadora. Município acessível ao cidadão. São Paulo: Fundação Prefeito Faria Lima CEPAM; 2001.

9. Associação Brasileira de Normas Técnicas. ABNT NBR 9050. Acessibilidade a edificações, mobiliário, espaços e equipamentos urbanos. São Paulo: ABNT; 2004. 97 p.

10. Secretaria Nacional de Transportes e da Mobilidade Urbana. Construindo uma cidade acessível. Brasil acessível: programa brasileiro de acessibilidade urbana. Caderno 2. Brasília: Ministério das Cidades; 2005. 
11. Ferrer MLP, Perracini MR, Ramos LR. Prevalência de fatores ambientais associados a quedas em idosos residentes na comunidade em São Paulo, SP. Rev Bras Fisioter 2004;8(2):149-54.

12. Ferreira MS, Souza AC, Souza FA. Mobilidade e acessibilidade na terceira idade: premissas para conceituação de produtos para idosos. Rio de Janeiro: Texto publicado no ENEDS; 2005.

13. Fernandes JC. Urbanismo e envelhecimento algumas reflexões a partir da cidade de Uberlândia. Rev Caminhos da Geografia 2000;1(2):31-49.

14. Pizzol KMSA, Ribeiro EL. O cotidiano urbano: uso e mobilidade nos passeios públicos em quatro bairros de João Pessoa - PB. Geografia 2005;14(2):145-56.

15. Rojas VBF. Contribuições para o planejamento de ambientes construídos destinados à convivência de idosos [dissertação de Mestrado]. Porto Alegre: Universidade Federal do Rio Grande do Sul; 2005.

16. Brasil. Decreto n. 5.296, de 2 de dezembro de 2004. Regulamenta as leis n. 10.048 e 10.098 , que dá prioridade de atendimento às pessoas e estabelece normas gerais e critérios básicos para a promoção da acessibilidade das pessoas portadoras de deficiência ou com mobilidade reduzida, e dá outras providências. Brasília: Presidência da República; 2004.

17. Brasil. Lei n. 10.098, de 19 de dezembro de 2000. Estabelece normas gerais e critérios básicos para promoção da acessibilidade das pessoas portadoras de deficiência ou com mobilidade reduzida, e dá outras providências. Brasília: Presidência da República; 2000.

18. Brasil. Lei n 10.257 , de 10 de julho de 2001. Dispões sobre o Estatuto da Cidade, estabelece diretrizes gerais da política urbana e dá outras providências.

19. Prefeitura Municipal de Caratinga. Plano diretor urbano de Caratinga. 1996.

20. Secretaria Nacional de Transportes e da Mobilidade Urbana. PlanMob. Caderno de referência para elaboração de plano diretor de transporte e da mobilidade. Brasília: Ministério das Cidades, 2007.

21. Gil AC. Como elaborar projetos de pesquisa. 4. ed. São Paulo: Atlas; 2002.

22. Brasil. Ministério da Saúde. Caderno de informação em saúde: município de Caratinga - MG [acesso em 9 maio 2007]. Disponível em: www.datasus.gov.br.

23. Beauvoir S. A velhice. 5. ed. Rio de Janeiro: Nova Fronteira; 1990.
24. Veras RP. País jovem com cabelos brancos: a saúde do idoso no Brasil. 2. ed. Rio de Janeiro: RelumeDumará: UNATI/UERJ; 1994.

25. Moreira MM. Envelhecimento da população brasileira: aspectos gerais. In: Wong LR, organizador. O envelhecimento da população brasileira e o aumento da longevidade - subsídios para políticas orientadas ao bem estar do idoso. Belo Horizonte: UFMG/CEDEPLAR; 2001.

26. Carvalho JAM, Andrade FCD. Envejecimiento de la población brasileña: oportunidades y desafios. In CEPAL, organizador. Encuentro Latinoamericaño y Caribeño sobre las personas de edad n. 2; 2002. p. 81-101.

27. Camarano AA; Kanso S, Mello JL. Como vive o idoso brasileiro? In: Camarano AA, organizadora. Os novos idosos brasileiros, muito além dos 60? Rio de Janeiro: IPEA; 2004. p. 25-73.

28. Ramos LR. Fatores determinantes do envelhecimento saudável em idosos residentes em centro urbano: Projeto Epidoso, São Paulo. Cad Saúde Pública 2003;19(3):793-7.

29. Wong LLR, Carvalho JA. O rápido processo de envelhecimento populacional do Brasil: sérios desafios para as políticas públicas. Rev Bras Est Pop 2006;23(1):5-26.

30. Parahyba MI, Simões CCS. A prevalência de Incapacidade funcional em idosos no Brasil. Ciênc Saúde Coletiva 2006;11(4):967-74.

31. Rosa TEC, Benício MHD, Latorre MRDO, Ramos LR. Fatores determinantes da capacidade funcional entre idosos. Rev Saúde Pública 2003;37(1):40-8.

32. Brasil. Instituto de Planejamento Econômico Aplicada. Impactos dos acidentes de trânsito. Brasília: IPEA; 2003 [acesso em 29 out 2008]. Disponível em: http//ww.ipea.gov.br.

33. Debert GG. A reinvenção da velhice: socialização e processos de reprivatização do envelhecimento. São Paulo: EdUSP; 2004.

34. Farias A. Las barreras arquitectónicas-urbanísticas y su implicância psicológica. Perspect Psicol 2004;1(1):89-94.

35. Brasil. Lei Ordinária de Caratinga-MG n. 3.025, de 28 de novembro de 2007. Dispõe sobre o Plano Diretor Participativo do Município de Caratinga-MG, e dá outras providências. Caratinga, MG: Prefeitura Municipal; 2007. 
36. Associação Brasileira de Normas Técnicas. ABNT NBR 12.255. Execução e utilização de passeios públicos. Rio de Janeiro: ABNT; 1990.

37. Brasil. Lei n. 10.741, de 1 de outubro de 2003. Dispõe sobre o Estatuto do Idoso e dá outras providências. Brasília: Presidencia da República; 2003.
38. Maciel ACC, Guerra RO. Fatores associados à alteração da mobilidade em idosos residentes na comunidade. Rev Bras fisioter 2005;9(1):17-23.

39. Rozestraten RJA. Envelhecimento, mobilidade e participação no trânsito. In: Neri AL, organizadora. Qualidade de vida e idade madura. Campinas: Papirus; 2002. p. 109-16.

Recebido: 25/10/2012

Revisado: 09/7/2013

Aprovado:15/8/2013 